\title{
In Vitro Evaluation System of Pharmacokinetics and Irradiation Effect in Boron Neutron Capture Therapy (BNCT) Using Three-Dimensional Artificial Human Tumor Tissue Model
}

\author{
Shintaro Ishiyama1 ${ }^{*}$, Yoshiya Asano², Minoru Suzuki ${ }^{3}$, Mitsuru Akashi ${ }^{4}$, Hiroshi Shimoda ${ }^{2,5}$ \\ ${ }^{1}$ Faculty of Science and Technology, Graduate School of Science and Technology, Hirosaki University, Bunkyo, Hirosaki, Aomori, \\ Japan \\ ${ }^{2}$ Department of Neuroanatomy, Cell Biology and Histology, Graduate School of Medicine, Hirosaki University, Zaifu, Hirosaki, \\ Aomori, Japan \\ ${ }^{3}$ Particle Radiation Oncology Research Center, Institute for Integrated Radiation and Nuclear Science, Kyoto University, \\ Asahiro-Nishi, Kumamori, Sennan, Osaka, Japan \\ ${ }^{4}$ Building Block Science, Graduate School of Frontier Biosciences, Osaka University, Yamada-Oka, Osaka, Japan \\ ${ }^{5}$ Department of Anatomical Science, Graduate School of Medicine, Hirosaki University, Hirosaki, Zaifu, Hirosaki, Aomori, Japan \\ Email: *ishiyama.shintaro@hirosaki-u.ac.jp
}

How to cite this paper: Ishiyama, S., Asano, Y., Suzuki, M., Akashi, M. and Shimoda, H. (2019) In Vitro Evaluation System of Pharmacokinetics and Irradiation Effect in Boron Neutron Capture Therapy (BNCT) Using Three-Dimensional Artificial $\mathrm{Hu}-$ man Tumor Tissue Model. Journal of Cancer Therapy, 10, 835-845.

https://doi.org/10.4236/jct.2019.1010071

Received: September 4, 2019

Accepted: October 18, 2019

Published: October 21, 2019

Copyright $\odot 2019$ by author(s) and Scientific Research Publishing Inc. This work is licensed under the Creative Commons Attribution International License (CC BY 4.0).

http://creativecommons.org/licenses/by/4.0/

\begin{abstract}
Boron neutron capture therapy (BNCT) is based on the incorporation of boron-containing drugs to cancer cells and the nuclear reaction of ${ }^{10} \mathrm{~B}$ atoms by thermal neutron irradiation results in tumor degeneration. For the development of this therapy, currently, long time and high cost consuming experiments using many animals are required. In this study, we constructed a new in vitro evaluation system for BNCT by combination of an artificial tumor tissue model, comprised of normal human dermal-derived fibroblast (NHDF) and human pancreatic cancer cell line BxPC3, and the optical plastic material CR-39 as a solid state nuclear track detector. Administration of boronophenylalanine $\left({ }^{10} \mathrm{BPA}\right)$ as a boron-containing drug and neutron irradiation up to $2.52 \times 10^{12} \mathrm{n} / \mathrm{cm}^{2}$ to the control tissue constructed by NHDF (NHDF3D) and BxPC3 cell loaded tissue (NHDF3D/BxPC3) resulted in detection of 1.6 times higher number of $\alpha$-ray/recoiled Li particle tracks in $\mathrm{NHDF} 3 \mathrm{D} / \mathrm{BxPC} 3$ in comparison to NHDF3D, demonstrating that putative irradiation damage to cancer cells can be evaluated by this system. On a cellular level, the hit number of $\alpha$-ray/recoiled Li particle tracks per single
\end{abstract}


BxPC3 cells and NHDF was evaluated as 5.46 and 1.71, respectively. The tumor and normal tissue ratio (T/N ratio) was 3.19, which was corresponded with those of BPA as $2-4$ that reported in the previous studies. This new in vitro evaluation system may provide a useful tool for a low cost, labor-saving, and non-animal method for the development of new boron-containing drugs or improvement of BNCT conditions.

\section{Keywords}

Boron Neutron Capture Therapy (BNCT), Boronophenylalanine ( $\left.{ }^{10} \mathrm{BPA}\right)$, Artificial Human Tumor Tissue Model, Cell Accumulation Method

\section{Introduction}

Boron neutron capture therapy (BNCT) is based on the nuclear reaction of nonradioactive isotope ${ }^{10} \mathrm{~B}$ atoms that absorb low-energy $(<0.5 \mathrm{eV})$ neutrons (thermal neutrons) disintegrate into an alpha $\left({ }^{4} \mathrm{He}\right)$ particle and a recoiled lithium nucleus $\left({ }^{7} \mathrm{Li}\right)$ that deposit high energy along their very short path $(<10 \mu \mathrm{m})$ and result in destroying of only malignant cells with ${ }^{10} \mathrm{~B}$ following thermal neutron irradiation [1]-[7]. Recently, ground-breaking results of BNCT for refractory cancer have been reported by clinical use of two boron-containing drugs, borocaptate sodium $\left({ }^{10} \mathrm{BSH}\right)$ and Boronophenylalanine $\left({ }^{10} \mathrm{BPA}\right)$. In regard to this new therapy, the improvement of the techniques and the development of new boron-containing drugs for higher performance are vigorously promoted [8] [9]. However, currently, long time and high cost consuming experiments using many animals are required for these studies. Moreover, the analysis and evaluation of pharmacokinetics and irradiation effects in human tissue at microscopic level are still difficult. Therefore, the establishment of more efficient in vitro experimental models is demanded for effective development of BNCT.

For this purpose, we focused on the usage of the artificially engineered tumor tissue models constructed by an extracellular matrix (ECM)-based three-dimensional tissue-constructing method, known as cell-accumulation technique [10] [11] [12] [13]. In previous studies, the in vitro human artificial tumor tissue models were prepared by seeding human cancer cells on the three-dimensional culture of normal human dermal-derived fibroblast (NHDF) involving vascular networks to apply for drug discovery, pathological model and diagnostic tool [10] [11] [12] [13].

In this study, we constructed new evaluation system for BNCT by combination of an artificial in vitro tumor tissue model, comprised of NHDF and pancreatic cancer cell line, BxPC3 [14] [15], and the optical plastic material CR-39 as a solid state nuclear track detector [6] [7]. Using this in vitro system and ${ }^{10} \mathrm{BPA}$ as a boron-containing drug, we evaluated the irradiation damage to the cancer cells on the tissue by analyzing the alpha-ray/recoiled Li particle tracks on CR-39. 


\section{Materials and Methods}

\subsection{Cells, Reagents and Instruments}

Normal human dermal-derived fibroblast (NHDFs) and red fluorescent protein (RFP)-labeled human pancreatic cancer cell line BxPC3 used in the experiment were purchased from LONZA (Walkersville, MD) and Anti-Cancer Japan (Ibaraki, Japan), respectively. Dulbecco's modified Eagle's medium (DMEM) (Wako, Osaka, Japan) containing 10\% fetal bovine serum (FBS) (Nichirei, Tokyo, Japan) was used to proliferate cells prior to construction of the tumor tissue model. The cells were cultivated at $37^{\circ} \mathrm{C}, 5 \%$ carbon dioxide. Bovine plasma-derived fibronectin (FN) and porcine skin gelatin (G) were purchased from Sigma-Aldrich (St. Louis, MO) and Wako Pure Chemical Industries, Ltd. (Osaka, Japan), respectively. Transwell inserts with porous polyester bottom (pore size: $0.4 \mu \mathrm{m}$ ) for 12-well culture plate (12 mm diameter, $112 \mathrm{~mm}^{2}$ area, cat. No. 3401) were purchased from CORNING Inc. (New York, NY). The boron drug ${ }^{10} \mathrm{BPA}$ (boronophenylalanine; $\mathrm{C}_{9} \mathrm{H}_{12} \mathrm{BNO}_{4}$, molecular weight 209.01, fructose complex) was kindly gifted from Interpharma Praha, a.s. (Komorany, Czechia). A solid state nuclear track detector CR-39, an optical plastic material with composition $\mathrm{C}_{12} \mathrm{H}_{18} \mathrm{O}_{7}$ [6] [7], was purchased from Cokin (Tokyo, Japan).

\subsection{Preparation of in Vitro Human Three-Dimensional Tumor Tissue Model}

Human three-dimensional tumor tissue was prepared by cell accumulation method [10] [11] [12] [13]. First, connective tissue-like structures were fabricated by three-dimensional lamination of NHDFs. As shown in Figure 1(a), NHDFs are cultured under the conditions mentioned above, then ECM-nano film (about $10 \mathrm{~nm}$ thick) was formed on each cell surface by coating cells with fibronectin and gelatin dissolved in Tris-HCl buffer according to previously published methods [10] [11] [12] [13]. The cells are seeded on the transwell inserts at a density of $27.2 \times 10^{5}$ cells/insert (8 layers) and cultured under the conditions of $5 \%$ carbon dioxide at $37^{\circ} \mathrm{C}$ for 12 to 24 hours. We regarded this connective tissue-like structure as an artificial human normal tissue model, termed as NHDF3D.

Next, RFP-labeled BxPC3 cells which have been cultured and proliferated were collected by trypsin treatment, washed, and uniformly seeded on the upper surface of NHDF3D at a density of 300 cells $/ \mathrm{mm}^{2}$, then further cultured for 24 hours under the above culture conditions. As shown in Figure 2(e) and Figure $2(\mathrm{f}), \mathrm{BxPC} 3$ cells proliferated on the surface of NHDF3D forming the groups with flat shape. We regarded this cancer-loaded NHDF3D as an artificial human tumor tissue model, termed as NHDF3D/BxPC3. In the present study, one case of NHDF3D and two cases of NHDF3D/BxPC3 were prepared by the methods mentioned above and were used for the experiments.

\subsection{BPA Immersion Treatment and Fixation}

The boronophenylalanine (BPA) solution $(3 \% \mathrm{w} / \mathrm{v})$ was diluted to a concentration 
of 40 ppm with DMEM containing $10 \%$ FBS. This is referred to as a BPA treatment solution. After removing the culture solution of NHDF3D or NHDF3D/ BxPC3, $750 \mu \mathrm{L}$ of BPA treatment solution was added, and incubated for 2 hours (BPA exposure) under conditions of $5 \%$ carbon dioxide at $37^{\circ} \mathrm{C}$ (Figure $1(\mathrm{~b})$ ). After that, the BPA treatment solution was removed and the tissues were washed 3 times with $0.01 \mathrm{M}$ phosphate-buffered saline (PBS, pH 7.3). Subsequently, the tissues were fixed by $4 \%$ paraformaldehyde/0.1M phosphate buffer $(\mathrm{pH} \mathrm{7.3)}$ for 30 minutes at room temperature shading the light. After the fixation, the cellular nucleus was stained by 4',6-diamidino-2-phenylindole (DAPI).

\subsection{Observation of BxPC3 Cell Distribution on the Artificial Tissues}

After the fixation, three holes were provided on the tissue using an $18 \mathrm{G}$ injection needle in order to provide alignment marks. Then the top surface of NHDF3D/BxPC3 was observed by fluorescence microscope BZ-X700 (Keyence, Osaka, Japan). The distribution of BxPC3 cells was visualized as a fluorescence image by RFP excitation (Figure 1(c)). A low magnification image including the entire tissue and high magnification images of various parts of each tissue were respectively obtained. A fluorescence image of NHDF3D was also obtained as a control.

(a)
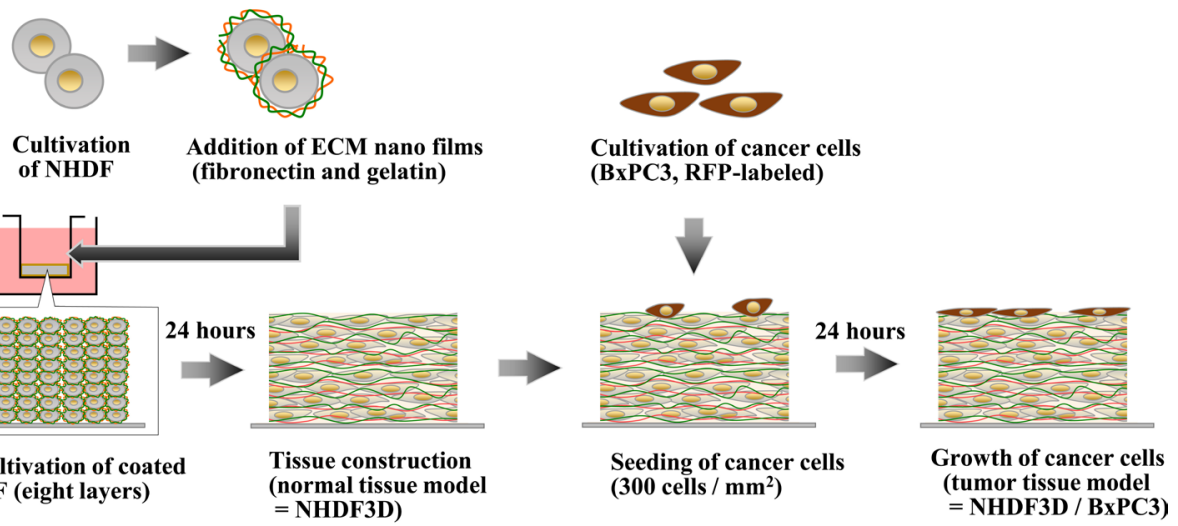

(b)

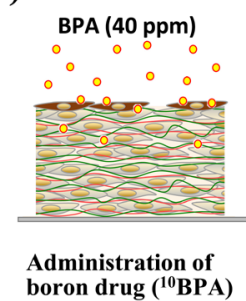

(c)

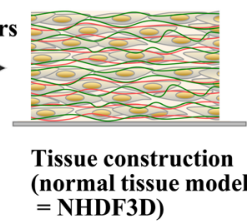

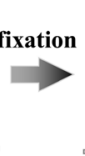

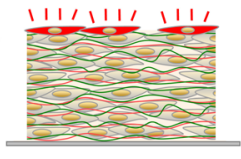

Fluorescent images of RFP-labeled cancer cells (d)

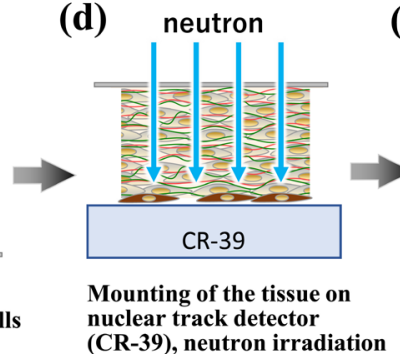

(e)

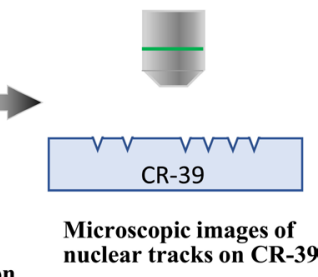

Figure 1. Procedures for detection of BNCT reaction by using in vitro three-dimensional artificial human tumor tissue model. (a): fabrication process of cancer cells-loaded human artificial tissue model. (b)-(e): operation of BNCT for the tissue models, and detection of cancer cell and nuclear track distribution. In the present paper, we adopted combination of an artificial tumor tissue model, comprised of normal human dermal-derived fibroblast (NHDF) and human pancreatic cancer cell line BxPC3. 


\subsection{Neutron Irradiation Experiment}

The above-mentioned NHDF3D or NHDF3D/BxPC3 in the transwell inserts were cut out with a knife together with the polyester base, mounted on the solid track detector CR-39 [6] [7] with close contact, and used as a sample for track image acquisition (Figure 1(d)). Irradiation experiments using these samples were conducted at the Heavy Water Neutron Irradiation Facility of Kyoto University Reactor (KUR), and irradiation was performed for 30 minutes under an irradiation flux of $1.4 \times 10^{9} \mathrm{n} / \mathrm{cm}^{2} / \mathrm{s}$ (total flux $=2.25 \times 10^{12} \mathrm{n} / \mathrm{cm}^{2}$ ) (Figure $1(\mathrm{~d}))$. After the neutron irradiation, the above sample was etched $(6 \mathrm{~N} \mathrm{NaOH}$, $70^{\circ} \mathrm{C} \times 2$ hours) to visualize the $\alpha$-ray/recoiled Li particle tracks generated on the CR-39 surface.

\subsection{Analysis of $\alpha$-Ray/Recoiled Li Particle Track Images}

The $\alpha$-ray/recoiled Li particle track image of etched CR-39 was taken using the bright field function of the fluorescence microscope BZ-X700 (Figure 1(e)). A low magnification image including the entire tissue mount and 10 random high magnification images were obtained respectively, and the following analysis was performed.

1) The whole tissue images of fluorescent $\mathrm{BxPC} 3$ cell distribution and the $\alpha$-ray/recoiled Li particle track distribution were compared referring to the position of three-hole markers, and the relationship of these distributions was observed.

2) Alpha-ray/recoiled Li particle tracks in the high magnification images were regarded as the particles, and quantitatively analyzed by using software FIJI (https://fiji.sc). Briefly, after binarizing the image, the tracks with more than 4 $\mu \mathrm{m}$ diameter were detected, and their number per unit area $\left(0.01 \mathrm{~mm}^{2}\right)$ and the track size were measured. Significant difference between the data from the artificial normal tissue model (NHDF3D) and artificial tumor tissue model (NHD$\mathrm{F} 3 \mathrm{D} / \mathrm{BxCP} 3$ ) was confirmed using student $t$-test.

\subsection{Measurement of Nuclear Size and Cell Size of BxPC3}

For measurement of nuclear size, $\mathrm{BxPC} 3$ cells cultivated on the cell culture dish were fixed by $4 \%$ paraformaldehyde/0.1 M phosphate buffer ( $\mathrm{pH} 7.3$ ) for $30 \mathrm{mi}$ nutes at room temperature shading the light. After the fixation, the cellular nuclei were stained by 4',6-diamidino-2-phenylindole (DAPI). The images of the cells were obtained by fluorescence microscope as shown in Figures 2(a)-(d). The photo images of nucleus with DAPI fluorescence were used for analysis of their area size using software FIJI (https://fiji.sc), then their diameter was estimated regarding the shape like circle.

For analysis of $\mathrm{BxPC} 3$ cell size, the high magnification fluorescent images of NHDF3D/BxPC3, as shown in Figure 2(e) and Figure 2(f), were used. Briefly, the shapes of RFP-fluorescent BxPC3 cells were extracted from the images, then the area size and putative square size were analyzed as the methods mentioned above. 

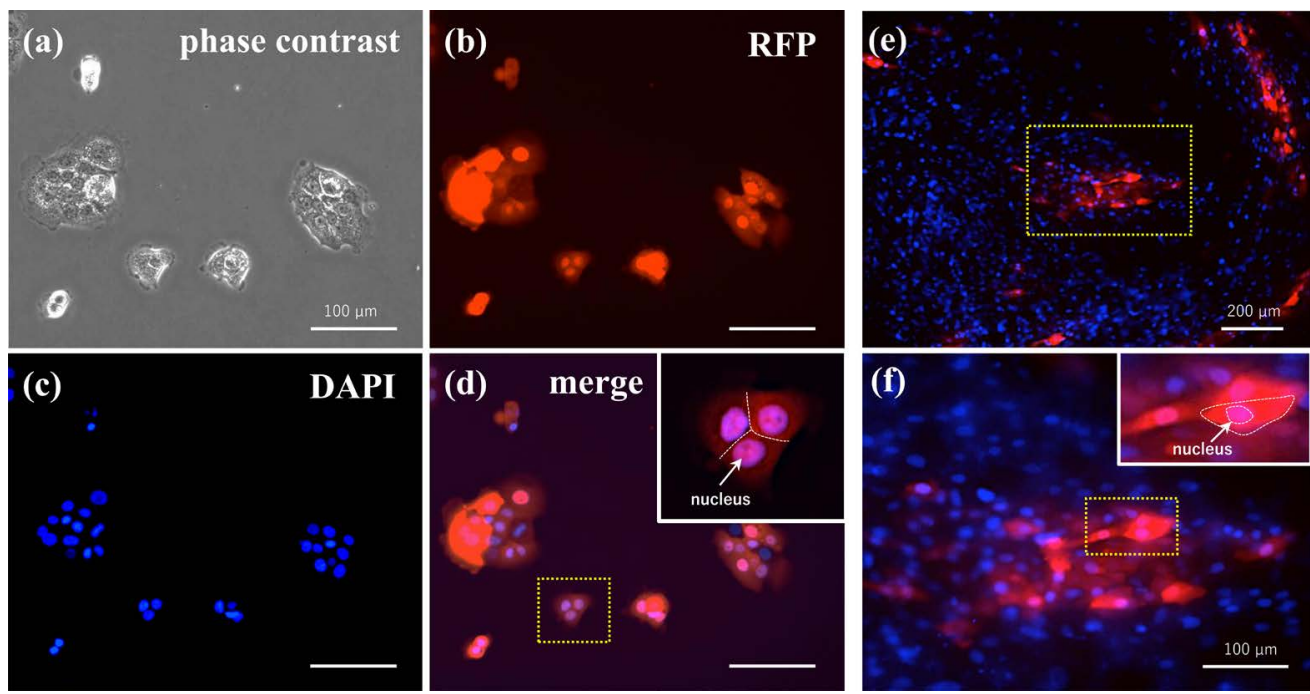

Figure 2. Fluorescent staining of BxPC3 cells and nucleus. (a)-(d) Microscopic images of BxPC3 cells on culture dish. (a): phase contrast image. (b): red fluorescence image of RFP-labeled BxPC3 cells. (c): cell nuclei with blue fluorescent staining by DAPI. (d): merged image of RFP and DAPI fluorescence. Inset: image of the cells in high magnification of yellow hatched box. White hatched line indicates the shape of the cells. (e) and (f): observation of BxPC3 cells on the tumor tissue model. (e): merged fluorescent image of BxPC3 cells and nucleus. BxPC3 cells with red fluorescence form flat shape and the small groups on the surface of the tissue. The nuclei of all cells in the tissue show blue fluorescence by DAPI staining. (f): higher magnification image of yellow hatched box in (e). Inset shows the shape of BxPC3 cell and its nucleus (white hatched line) on the tissue. By this fluorescence optical tissue observation, it was possible to grasp in detail the nucleus, cell tissue structure, shape, and distribution state of the tumor cell used when manufacturing the artificial tumor tissue.

\section{Results and Discussions}

\subsection{Distribution of the BxPC3 Cells and Alpha-Ray/Recoiled Li Particle Tracks on the Tissue Models}

Low-magnification images of NHDF3D and NHDF3D/BxPC3 (two cases) detecting RFP fluorescence were shown in Figures 3(a)-(c). Although the BxPC3 cells were seeded over the artificial tissue in regular cell concentration, slight heterogeneity of cell distribution was observed after the cultivation for 24 hours. The parts with intense fluorescence denoting high density of BxPC3 cells were indicated by yellow circles in the figures. The $\alpha$-ray/recoiled Li particle tracks in corresponded parts of Figures 3(a)-(c) were shown in Figures 3(a')-(c'). Asterisks indicate the marking holes to match the position of the tissue images and the track images. The concentration of $\alpha$-ray/recoiled $\mathrm{Li}$ particle tracks in $\mathrm{NHDF} 3 \mathrm{D} / \mathrm{BxCP} 3$ is higher than those of NHDF3D. Moreover, relatively high concentration of the $\alpha$-ray/recoiled Li particle tracks was observed at the yellow circles in Figure 3(b) and Figure 3(c). These results suggested that the preferential incorporation of ${ }^{10} \mathrm{~B}$ into $\mathrm{BxPC} 3$ cells and their distribution on the tumor tissue model were reflected by the $\alpha$-ray/recoiled Li particle track images.

Figure 4(b), Figure 4(b'), Figure 4(c), and Figure 4(c') showed the higher magnification images of the white boxes on NHDF3D/BxPC3 in Figure 3. Figure 4(a) and Figure 4(a') were the images of NHDF3D as control. In Figure 4(b) 


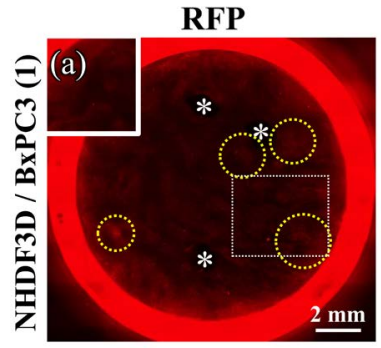

(b)

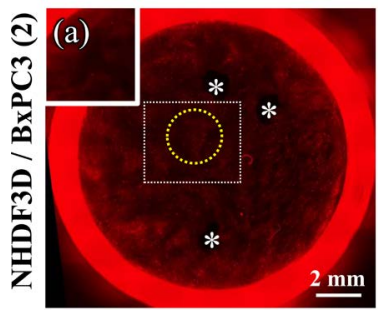

(c)

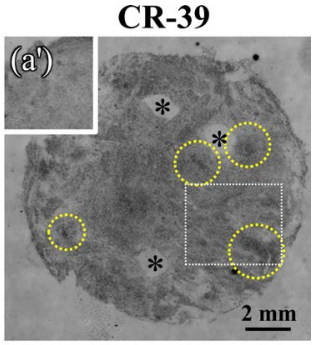

(b')

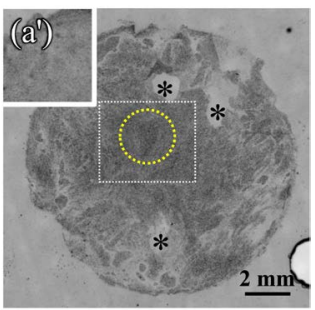

$\left(c^{\prime}\right)$

Figure 3. Comparison of BxPC3 cell distribution and $\alpha$-ray/recoiled Li particle track distribution in low magnification. (a)-(c): red fluorescent image of the tissue models. (a): NHDF3D as a control without BxPC3 cells. (b) and (c): two cases of cancer-loaded tissue; NHDF3D/BxPC3 (1) and NHDF3D/BxPC3 (2). Asterisks indicate the positions of marking holes to coincide the cell distribution images and the track distribution images. Slight heterogeneity of BxPC3 cell distribution is observed by the uneven intensity of red fluorescent. Yellow hatched circles indicate the parts with relatively intense red fluorescence denoting high concentration of BxPC3 cells. White hatched indicates the area that is shown in Figure 4 in high magnification. (a')-(c'): $\alpha$-ray/recoiled Li particle track distribution of (a)-(c). The tracks are observed as the gray colors with several concentration. The relatively high concentration parts in ( $\left.b^{\prime}\right)$ and ( $c^{\prime}$ ) indicated by hatched yellow circles correspond to those of (b) and (c). By observing the fluorescence optical tissue, we were able to grasp the nuclei, cellular tissue structure, shape, and distribution state of the manufactured artificial tumor tissue before BNCT treatment.

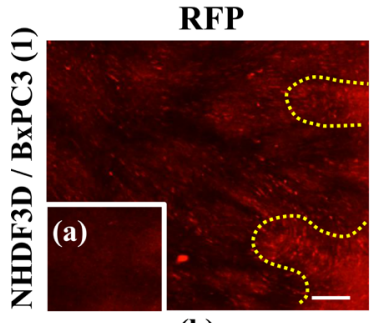

(b)

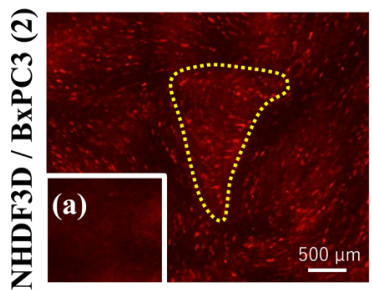

(c)
CR-39

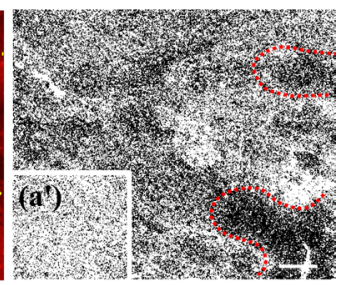

(b')

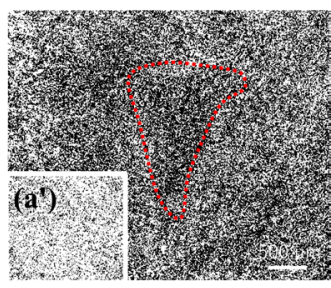

(c')

Figure 4. Comparison of BxPC3 cell distribution and $\alpha$-ray/recoiled Li particle track distribution in higher magnification. (a)-(c): red fluorescent image of the tissue models. (a): NHDF3D. (b) and (c): NHDF3D/BxPC3 (1) and NHDF3D/BxPC3 (2). The presence of BxPC3 cells can be confirmed by red fluorescent mottles in (b) and (c). The areas surrounded by yellow hatched lines indicate the parts with relatively high concentration of BxPC3 cells. (a')-(c'): $\alpha$-ray/recoiled Li particle track distribution of (a)-(c). The areas surrounded by red hatched lines in (b') and (c') correspond to the areas with high concentration of BxPC3 cells in (b) and (c). By this fluorescence optical tissue observation, it was possible to grasp in detail the tissue changes that occurred in the artificial tumor tissue before and after BNCT. Fluorescence optical tissue observations made it possible to grasp in detail the tissue changes that occurred in the normal and tumor tissue parts of the artificial tumor tissue after BNCT treatment. 
and Figure 4(c) with RFP fluorescence, BxPC3 cells were observed as small fluorescent clusters. In the control image Figure 4(a), the fluorescent clusters were not observed. In Figures $4\left(\mathrm{a}^{\prime}\right)-\left(\mathrm{c}^{\prime}\right)$, the $\alpha$-ray/recoiled Li particle tracks were observed as small dots, reflecting the intensity of the emission. Since the contrast between NHDF3D (a') and NHDF3D/BxPC3 ( $b^{\prime}$ or c') was obvious, the BxPC3 cells-dependent incorporation of ${ }^{10} \mathrm{~B}$ resulting the $\alpha$-ray/recoiled $\mathrm{Li}$ particle emission was clearly detected in this system. Furthermore, as shown by the area surrounded with yellow and red hatched lines, the high density of BxPC3 cells on the tissue in Figure 4(b) and Figure 4(c) was comparative with the high intensity of the $\alpha$-ray/recoiled Li particle emission in (b') and (c'). From these results, it was suggested that ${ }^{10} \mathrm{BPA}$ was abundantly taken in proportion to the tumor concentration locally at a high tumor concentration site.

\subsection{Quantitative Analysis of $\alpha$-Ray/Recoiled Li Particle Tracks in NHDF3D and NHDF3D/BxCP3 Samples}

To investigate detailed $\alpha$-ray/recoiled Li particle track distribution and number of tracks in NHDF3D and NHDF3D/BxCP3 samples, high magnification images of $\alpha$-ray/recoiled Li particle tracks on CR-39 (Figures 5(a)-(c), photo) were quantitatively analyzed. After the process of binarization with the track detection as the particles (Figures 5(a)-(c), binary), those with more than $4 \mu \mathrm{m}$ diameter were selected, and their total number and sizes were measured (Figures 5(a)-(c), particle analysis). The results are shown in Figure 4(d) and Figure 4 (e). The number of $\alpha$-ray/recoiled Li particle tracks of NHDF3D/BxCP3 was about 1.6 times higher than that of NHDF3D (Figure 5(d)).

Next, we evaluated the hit number of $\alpha$-ray/recoiled Li particle tracks per single cell on the top layer of NHDF3D and NHDF3D/BxCP3 as shown in Table 1. In the control tissue NHDF3D, the number of $\alpha$-ray and recoiled Li particles tracks $\left(H_{B}\right)$ was $51.52 / 0.01 \mathrm{~mm}^{2}$ as the value of Figure $5(\mathrm{~d})$. Whereas, $H_{B}$ in NHDF3D/BxCP3 (1) and NHDF3D/BxCP3 (2) was 81.10 and $87.68 / 0.01 \mathrm{~mm}^{2}$, respectively. The increased $\alpha$-ray and recoiled Li particles tracks by seeded and grown BxPC3 cells $\left(\Delta H_{B}\right)$ were calculated by $\left[H_{B}(\mathrm{NHDF} 3 \mathrm{D})-H_{B}(\mathrm{NHDF} 3 \mathrm{D} / \mathrm{BxPC} 3)\right]$. The cell number $\left(H_{\text {cell }}\right)$ of NHDF in the top layer of NHDF3D was estimated as 30.09 cells $/ 0.01 \mathrm{~mm}^{2}$ according to the seeded cell number at the construction of tissue model. The $H_{\text {cell }}$ of BxPC3 was estimated as 6.02 cells $/ 0.01 \mathrm{~mm}^{2}$ in NHDF3D/BxCP3 (1) and (2) according to the seeded cell number and duplication at 24 hours after seeding that was confirmed in previous study (data not shown).

By using these data, we estimated tracks per single NHDF $\left[\left(H_{B} / H_{\text {cell }}\right)_{\mathrm{NHDF}}\right]$ in top layer of NHDF3D as 1.71, and that tracks par single BxPC3 cell $\left[\left(H_{B} / \Delta H_{\text {cell }}\right)_{\mathrm{BxPC} 3}\right]$ in NHDF3D/BxCP3 (1) and (2) as 4.91 and 6.01 (average: 5.46). Therefore the ratio was estimated as $2.87\left[\left(H_{B} / \Delta H_{\text {cell }}\right)_{\mathrm{BxPC}(1)} /\left(H_{B} / H_{\text {cell }}\right)_{\mathrm{NHDF}}\right]$ and $3.51\left[\left(H_{B} / \Delta H_{\text {cell }}\right)_{\mathrm{BxPC}(2)} /\left(H_{B} / H_{\text {cell }}\right)_{\mathrm{NHDF}}\right]$ respectively, and the averaged value was 3.19. These values corresponded with the tumor and normal tissue ratio $(\mathrm{T} / \mathrm{N}$ ratio) of BPA as 2 - 4 that reported in the previous studies including animal 


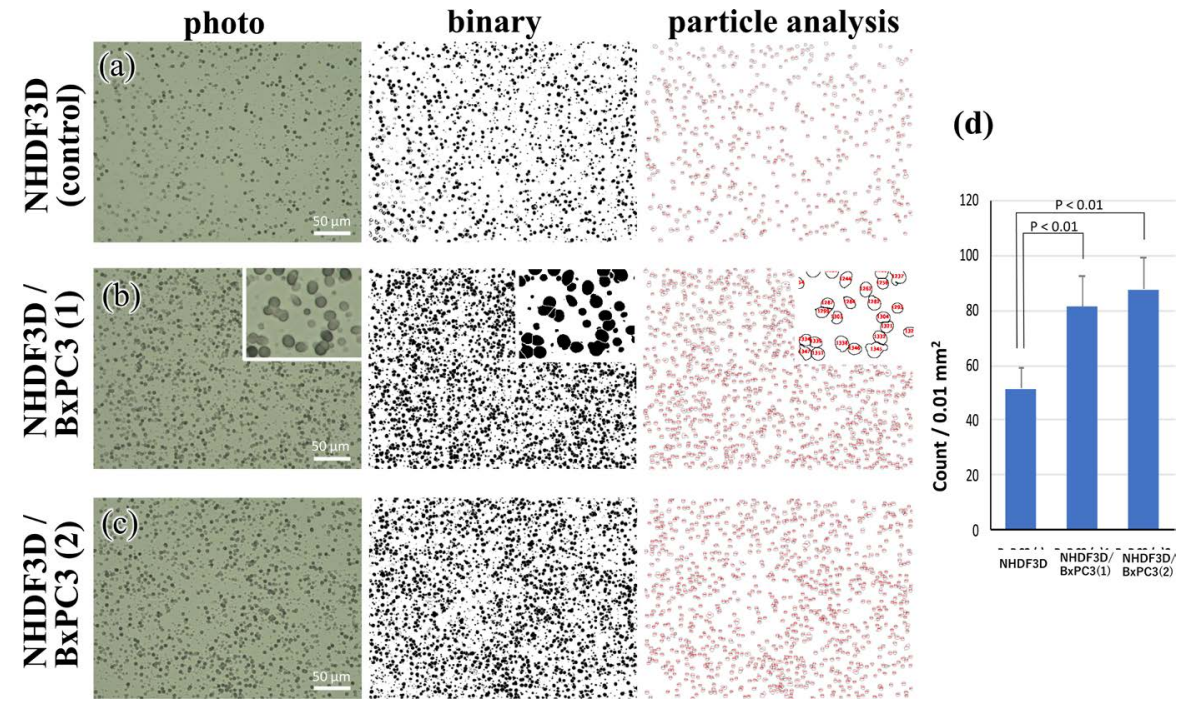

Figure 5. Quantitative analysis of $\alpha$-ray/recoiled Li particle tracks in NHDF3D and NHDF3D/BxCP3 samples. High magnification photo images of $\alpha$-ray/recoiled Li particle track distribution were processed by using software Fiji for quantitative analysis of $\alpha$-ray/recoiled Li particle tracks. (a): NHDF3D as a control. (b) and (c): NHDF3D/BxPC3 (1) and NHDF3D/BxPC3 (2). The binary data were prepared from the photo images and particle analysis was performed to count the number of the tracks and measure the of their size. (d): the number of the particle tracks in $0.01 \mathrm{~mm}^{2}$. By further expanding the tissue change sites in the normal tissue and tumor tissue in the artificial tumor tissue after BNCT treatment, it was possible to grasp in detail the $\alpha$ track shape and distribution that occurred after BNCT treatment.

Table 1. Evaluation of $\alpha$-ray/recoiled Li particle tracks per single cell on the top layer of NHDF3D and NHDF3D/BxCP3.

\begin{tabular}{|c|c|c|c|c|}
\hline Tissue model & $\begin{array}{c}H_{B} \\
\left(\mathrm{n} / 0.01 \mathrm{~mm}^{2}\right)\end{array}$ & $\begin{array}{c}\Delta H_{B} \\
\left(\mathrm{n} / 0.01 \mathrm{~mm}^{2}\right)\end{array}$ & $\begin{array}{c}H_{\text {cell }}\left(\text { cells } / 0.01 \mathrm{~mm}^{2},\right. \\
\text { top layer })\end{array}$ & $\begin{array}{c}\text { tracks/cell } \\
\text { (n/cell) }\end{array}$ \\
\hline NHDF3D & 51.52 & - & NHDF: 30.09 & 1.71 \\
\hline NHDF3D/BxPC3 (1) & 81.10 & 29.58 & BxPC3 (putative): 6.02 & 4.91 \\
\hline NHDF3D/BxPC3 (2) & 87.68 & 36.16 & BxPC3 (putative): 6.02 & 6.01 \\
\hline
\end{tabular}

$H_{B}$ : the number of $\alpha$-ray and recoiled Li particle tracks per $0.01 \mathrm{~mm}^{2} ; H_{\text {cell }}$ cell number per $0.01 \mathrm{~mm}^{2}$.

experiments [16].

From these results, it was suggested that our in vitro method can reproduce the in vivo T/N ratio of BPA and available for evaluation system of pharmacokinetics.

In conclusion, our in vitro model of tumor tissue for BNCT demonstrated the pharmacokinetics of BPA and the efficacy of neutron irradiation by direct observation of $\alpha$-ray/recoiled Li particle tracks that are corresponding to the distribution of BxPC3 cells. Moreover, the evaluated number of $\alpha$-ray/recoiled Li particle tracks per single BxPC3 cell or NHDF provided the comparable value with $\mathrm{T} / \mathrm{N}$ ratio of $\mathrm{BPA}$ in the previous studies. These results suggested that our in vitro model can be applied for a reproducible and high throughput method which enables to develop new boron-containing reagents from many drug can- 
didates for BNCT without any animal experiments. Our model also can be used to evaluate the optimum conditions of BNCT such as dose of boron-containing drugs and the irradiated intensity (power and time) of neutron to the patients. Particularly, the examination using cancer cells obtained from each individual patient may enable to provide the safety and effectiveness for personalized BNCT.

As a limitation of this system, the detectable $\alpha$-ray/recoiled Li particle tracks by CR-39 is restricted only those from the top layer of the artificial tissue, so that the other cancer cells such that rapidly infiltrate into the tissue cannot be applied. Three-dimensional detection of boron-containing drugs or irradiation damages distribution may extremely increase the value of this evaluation system as a tool for the development of BNCT and related medical studies.

\section{Conflicts of Interest}

The authors declare no conflicts of interest regarding the publication of this paper.

\section{References}

[1] Masunaga, S., Sakurai, Y., Tanaka, H., et al. (2014) The Dependency of Compound Biological Effectiveness Factors on the Type and Concentration of Administered Neutron Capture Agents in Boron Neutron Capture Therapy. Springerplus, 3, Article No. 128. https://doi.org/10.1186/2193-1801-3-128

[2] Ishiyama, S., Baba, Y., Fujii, R., Nakamura, M. and Imahori, Y. (2012) Synthesis of Lithium Nitride for Neutron Production Target of BNCT by In-Situ Lithium Deposition and Ion Implantation. Nuclear Instruments and Methods in Physics Research, 293, 42-47. https://doi.org/10.1016/j.nimb.2012.09.016

[3] Ishiyama, S., Baba, Y., Fujii, R., Nakamura, M. and Imahori, Y. (2013) Thermal Stability of BNC Neutron Production Target Lithium Synthesized by In-Situ Lithium Deposition and Ion Implantation. Materials Transactions, 54, 1760-1764. https://doi.org/10.2320/matertrans.M2013062

[4] Ishiyama, S. and Imahori, Y. (2014) Deterministic Parsing Model of CBE Factor for Intracellular ${ }^{10}$ Boron Distribution in Boron Neutron Capture Therapy. Journal of Cancer Therapy, 5, 1388-1398. https://doi.org/10.4236/jct.2014.514140

[5] Ishiyama, S., Imahori, Y., Itami, J. and Hanna, V. (2015) Determination of the Compound Biological Effectiveness (CBE) Factors Based on the Ishiyama-Imahori Deterministic Parsing Model with the Dynamic PET Technique. Journal of Cancer Therapy, 6, 759-766. https://doi.org/10.4236/jct.2015.68083

[6] Suzuki, M., et al. (2014) Boron Neutron Capture Therapy Outcomes for Advanced or Recurrent Head and Neck Cancer. Journal of Radiation Research, 55, 146-153. https://doi.org/10.1093/jrr/rrt098

[7] Suzuki, M., et al. (2007) First Attempt of Boron Neutron Capture Therapy (BNCT) for Hepatocellular Carcinoma. Japanese Journal of Clinical Oncology, 37, 376-381. https://doi.org/10.1093/jico/hym039

[8] Ichihashi, M., et al. (1982) Specific Killing Effect of 10B1-Para-Boronophenylalanine in Thermal Neutron Capture Therapy of Malignant Melanoma, in Vitro Radiobiological Evaluation. Journal of Investigative Dermatology, 78, 215-218. https://doi.org/10.1111/1523-1747.ep12506489

[9] Hiratsuka, J., et al. (1982) RBEs of Thermal Neutron Capture Therapy and ${ }^{10} \mathrm{~B}(\mathrm{n}, \alpha)^{7}$ 
Li Reaction on Melanoma Bearing Hamsters. Pigment Cell Research, 2, 352-355. https://doi.org/10.1111/j.1600-0749.1989.tb00219.x

[10] Matsusaki, M. (2012) Development of Three-Dimensional Tissue Models Based on Hierarchical Cell Manipulation Using Nanofilms. Bulletin of the Chemical Society of Japan, 85, 401-414. https://doi.org/10.1246/bcsj.20110194

[11] Matsusaki, M.C.P., Case, C.P. and Akashi, M. (2014) Three-Dimensional Cell Culture Technique and Pathophysiology. Advanced Drug Delivery Reviews, 74, 95-103. https://doi.org/10.1016/j.addr.2014.01.003

[12] Asano, Y., Odagiri, T., Oikiri, H., Matsusaki, M., Alashi, M. and Shimoda, H. (2017) Construction of Artificial Human Peritoneal Tissue by Cell-Accumulation Technique and Its Application for Visualizing Morphological Dynamics of Cancer Peritoneal Metastasis. Biochemical and Biophysical Research Communications, 494, 213-219. https://doi.org/10.1016/j.bbrc.2017.10.050

[13] Nishiguchi, A., Matsusaki, M., Kano, M.R., Nishihara, H., Okano, D., Asano, Y., Shimoda, H., Kishimoto, S., Iwai, S. and Akashi, M. (2018) In Vitro 3D Blood/Lymph-Vascularized Human Stromal Tissues for Preclinical Assays of Cancer Metastasis. Biomaterials, 179, 144-155. https://doi.org/10.1016/j.biomaterials.2018.06.019

[14] Tan, M.H., Nowak, N.J. and Loor, R. (1986) Characterization of a New Primary Human Pancreatic Tumor Line. Cancer Investigation, 4, 15-23. https://doi.org/10.3109/07357908609039823

[15] Deer, E.L., Hernandes, J.G. Coursen, J.D., Shear, J.E., et al. (2010) Phenotype and Genotype of Pancreatic Cancer Cell Lines. Pancreas, 39, 425-435. https://doi.org/10.1097/MPA.0b013e3181c15963

[16] Coderre, J.A. and Morris, G.M. (1999) The Radiation Biology of Boron Neutron Capture Therapy. Radiation Research, 151, 1-18. https://doi.org/10.2307/3579742 